\title{
Effects of dissolved organic matter derived from forest leaf litter on biodegradation of phenanthrene in aqueous phase
}

Dan $\mathrm{CAI}^{1}$, Xiuhong YANG ${ }^{1,2}$, Shizhong WANG ${ }^{1,3^{*}}$, Yuanqing CHAO ${ }^{1,3}$, J.L. Morel ${ }^{4,5}$, Rongliang QIU ${ }^{1,3 *}$

1 School of Environmental Science and Engineering, Sun Yat-sen University, Guangzhou 510275, China

2 Experiment Teaching Center, Sun Yat-sen University Zhuhai Campus, Zhuhai 519082, China

3 Guangdong Provincial Key Laboratory of Environmental Pollution and Remediation Technology (Sun Yat-sen University), Guangzhou 510275, China

4 Université de Lorraine, Laboratoire Sols et Environnement, UMR 1120, TSA 40602, F-54518 Vandœuvre-lès-Nancy, France

5 INRA, Laboratoire Sols et Environnement, UMR 1120, TSA 40602, F-54518 Vandœuvre-lès-Nancy, France

*Corresponding author

Rongliang QIU: Tel.: +86 20 84113454; Fax: +86 20 84113454;

Email: eesqrl@mail.sysu.edu.cn

Shizhong WANG: Tel.: +86 20 8411215; Fax: +86 20 84110508;

Email: wshizh2@mail.sysu.edu.cn

\begin{abstract}
Dissolved organic matter (DOM) released from forest leaf litter is potentially effective for the degradation of polycyclic aromatic hydrocarbons (PAHs), yet the inherent mechanism remains
\end{abstract}


insufficiently elucidated. In this study, we investigated the effects of DOM derived from Pinus elliottii and Schima superba leaf litter on the degradation of phenanthrene by the phenanthrene degrading bacterium Sphingobium sp. Phe-1. DOM from different origins and at a large range of concentrations enhanced the degradation rate of phenanthrene. DOM derived from P. elliottii leaf litter decomposed for 12 months used at a concentration of $100 \mathrm{mg} / \mathrm{L}$ yielded the highest degradation rate $(16.9 \%$ in 36 h) and shortened the degradation time from $48 \mathrm{~h}$ to $24 \mathrm{~h}$. Changes in the composition of DOM during degradation as measured by EEMs-FRI showed that proteins and tyrosine in the DOM supplied readily available nutrients that stimulated biological activity of Phe-1, increasing its growth rate and catechol 2,3-dioxygenase activity. Simultaneously, fulvic acid and humic acid in the DOM enhanced phenanthrene bioavailability by increasing the solubility and mass transfer of phenanthrene, enhancing the uptake kinetics of Phe-1, and increasing the bacteria's direct access to DOM-associated phenanthrene. Humic acid was co-metabolized by Phe-1, resulting in further stimulation of phenanthrene degradation.

Keywords: phenanthrene; microbial degradation; dissolved organic matter (DOM); leaf litter; co-metabolism of HA

\section{Introduction}

Polycyclic aromatic hydrocarbons (PAHs) are organic pollutants with stable ring structures, poor water solubility, and high octanol-water partition coefficients. PAHs can persist in soils and sediments, where they pose a serious threat to the environment and human health $[1,2]$. The forest canopy can 
remove PAHs from the atmosphere by interception, adsorption, and absorption, and subsequently the PAHs can return to the soil via wet or dry deposition (including litter fall) [3, 4]. Hence, the soil is the main reservoir for POPs (Persistent Organic Pollutants) including PAHs. It was reported that the yearly fluxes of the PAHs are about $53.3-80 \mathrm{mg} / \mathrm{year} / \mathrm{m}^{2}$, of which litterfall and throughfall contribute to only $40 \mu \mathrm{g} / \mathrm{year} / \mathrm{m}^{2}$ and $213 \mu \mathrm{g} / \mathrm{year} / \mathrm{m}^{2}$, respectively [5]. Among the various PAHs, phenanthrene is the dominant one [6], and its concentration in the forest soil is the highest as well $[7,8]$. Although microbial degradation is the primary way that PAHs are removed from forest soils $[2,9,10]$, this biodegradation occurs to a limited extent in natural environments because of the low bioavailability of PAHs (they have low water solubility and are inclined to adsorb to the soil solid phase) and the low adaptability or activity of microbes [11-13]. Many studies have reported that degradation of PAHs could be enhanced by stimulation of microbial growth through addition of a supplemental carbon source or other microbial nutrients as well as by addition of humic acid (HA), fulvic acid (FA), or a surfactant/bio-surfactant to promote the bioavailability of PAHs by enhancing their apparent solubility and diffusive mass transfer $[11,12,14,15]$. However, much research in this area focus on adding a single material (such as fulvic acid, humic acid, glucose or peptone) to promote microbial growth or enhance the bioavailability of PAHs, which is, more or less, insufficient to elucidate the potentially complex function of exogenous amendments in the natural environment.

Nevertheless, though the effect of the dissolved organic matters (DOM) on PAHs degradation has been studied in some other researches, the interacting mechanisms remain unclear [16-20]. Up to date, the effect of DOM on the degradation of PAHs was mainly explicated by the multiple actions of DOM 
against both PAHs and their degrading microorganisms [21-23]. On the one hand, DOM can form complexes or micelle with PAHs because of its special structure or performance similar to surfactant, thereby affecting their bioavailability and toxicity [24]. Some authors suggested that addition of DOM decreases the solubility and consequently the bioavailability of PAHs, which seems like a drawback in their degradation $[25,26]$. However, other researchers concluded that the solubility decrease will not influence the degradation of PAHs because the DOM could bind PAHs and hence increase the diffusive flux of PAHs, making them much more available to bacteria [21-23, 27]. By this way, exemplary cases reported by Ortega-Calvo et al. and Haderlein et al. showed that in the presence of HA-clay in liquid culture, phenanthrene was more rapidly mineralized [21, 28]. On the other hand, to acquire sufficient nutrients, the bacteria will preferentially adsorb to DOM rather than PAHs, which could favor the growth of microbial strains active in biodegradation, and subsequently induce the expression of intermediate degradation enzymes by these strains [29-31]. But it should be noted, though reported in limited literature, that the DOM will also inhibit the cell adhesion to the pollutant source and inhibit the degradation of PAHs [22]. Nevertheless some other studies proved that contaminants adsorbed to mineral-HA are bioavailable, and sorption of both the bacteria and the PAHs to HA stimulates PAHs degradation [23, 28]. From the foregoing, it could be concluded that the influence of DOM on the degradation of PAHs is strongly compound dependent, which is closely related to the binding sites and functioning groups embedded in different compounds of the DOM.

DOM in soil is a mixture or continuum of organic molecules with different structures and molecular weights. In view of its diverse composition, DOM was regarded as part of bio-stimulation 
strategies to accelerate the biodegradation of PAHs [9, 32, 33] through its various compounds by influencing either the PAHs bioavailability or the bacterial process. Toyama (2011) [34] proved that the phenolic compounds of Phragmites australis root exudates acted as a carbon source supporting growth and induced benzo[a]pyrene-degrading activity of the a Mycobacterium strain. Yi (2007) [35] suggested that linoleic acid was the major substance that stimulated PAHs degradation based on comparison of the chemical compositions of the effective plants. Meng (2011) [36] proved that lipophilic extract was the major rhizodeposit enhancing pyrene biodegradation, while water-soluble extract stimulated microbial growth most efficiently. The DOM released from forest leaf litter is an important source of organic carbon in the forest system. However, the mechanisms responsible for these effects are not very clear. For example, which fraction of DOM contributes to the bioavailability of PAHs and/or promote the functioning of the degrading strain, which DOM fractions act on PAHs, and which process come first? How to enhance both the bioavailability of PAHs and the biological activity of degrading bacteria through the use of DOM are questions addressed by the present study, because the best biological stimulation strategy will exploit the synergy between these factors[37].

In the current study, phenanthrene was chosen as a representative PAH (the concentration of phenanthrene in the forest soil is highest among the 16 PAHs in south China [7], our previous study also showed similar result (Fig.S12)), and a bacterial strain (Sphingobium sp. Phe-1) with high degradation efficiency was selected by screening bacteria collected from a site highly contaminated by PAHs. DOM was derived from Pinus elliottii and Schima superba leaf litter that had decomposed in the wild for $0,2,5,8,12$ months. Experiments were conducted to study the effect of DOM on the 
degradation of phenanthrene by the Phe-1 strain and to better understand the interacting mechanisms in the DOM-PAH-microorganism system. Excitation-emission matrix fluorescence spectroscopy coupled with fluorescence regional integration (EEMs-FRI) was used to determine the composition of DOM before and after degradation of phenanthrene based on analysis of five excitation-emission regions[38].

\section{Materials and methods}

\subsection{Chemicals}

Phenanthrene (TGI, Japan, purity > 97\%) was obtained from Aldrich Chemical Co. Phenanthrene-d10 and M-terphenyl (O2Si, USA, radiochemical purity > 99.99\%) were supplied by Sigma Chemical Co.

\subsection{Culture medium}

The Sphingobium sp. Phe-1 strain used in the present research was capable of utilizing phenanthrene as a source of carbon and energy, as determined using minimal medium (MM) containing, in $1 \mathrm{~L}$ Milli-Q water (Millipore Massachusetts, USA): $3 \mathrm{~g}\left(\mathrm{NH}_{4}\right)_{2} \mathrm{SO}_{4}, 0.5 \mathrm{~g} \mathrm{KH}_{2} \mathrm{PO}_{4}, 0.5 \mathrm{~g}$ $\mathrm{Na}_{2} \mathrm{HPO}_{4}, 0.2609 \mathrm{~g} \mathrm{MgSO}_{4}$, and $1 \mathrm{~mL}$ trace elements, $\mathrm{pH}$ 7.0. The trace element solution contained, per liter: $0.3 \mathrm{~g} \mathrm{FeCl}_{3}, 0.3 \mathrm{~g} \mathrm{FeSO}_{4} \cdot 7 \mathrm{H}_{2} \mathrm{O}, 0.15 \mathrm{~g} \mathrm{MnSO}_{4} \cdot \mathrm{H}_{2} \mathrm{O}, 0.14 \mathrm{~g} \mathrm{ZnSO}_{4}$, and $0.2 \mathrm{~g} \mathrm{CoCl}_{2}$ [39]. The MM was sterilized by autoclaving for 30 minutes at $121^{\circ} \mathrm{C}$ using an ALD CL-32L Autoclave (Kyoto, Japan) and was cooled to room temperature before use. 


\subsection{Bacterium}

A phenanthrene-degrading bacterium, Sphingobium sp. Phe-1, with high degradation efficiency was selected by screening bacteria collected from a site highly contaminated by PAHs near a refinery in Qingyuan, Guangdong province. According to the literature [40], soil suspension was prepared by placing $10 \mathrm{~g}$ fresh soil in $90 \mathrm{~mL}$ Mill-Q water and shaking for $30 \mathrm{~min}$ at $180 \mathrm{rpm}$ at $30{ }^{\circ} \mathrm{C}$. Then $1 \mathrm{~mL}$ soil suspension was inoculated into $250 \mathrm{~mL}$ Erlenmeyer flask containing $99 \mathrm{~mL}$ of sterilized $\mathrm{MM}$ supplemented with $1 \mathrm{mg}$ of phenanthrene and incubated aerobically for $5 \mathrm{~d}$ at $30{ }^{\circ} \mathrm{C}$ at $160 \mathrm{rpm}$. Subsequent incubations and isolations were conducted by following the same procedure as the literature [40], but the amount of phenanthrene was increased gradually by 1, 5, 10, 20, $25 \mathrm{mg}$. Further identification was carried out by phylogenetic analysis followed by the sequencing of $16 \mathrm{~S}$ rDNA. The Phe-1 strain incubation conditions was investigated [40] and the best growth condition of Phe-1 was achieved with $100 \mathrm{mg} / \mathrm{L}$ phenanthrene in a minimal medium at $\mathrm{pH} 7.0$, with shaking at $160 \mathrm{rpm}$ and a temperature of $35^{\circ} \mathrm{C}$.

\subsection{DOM}

Pinus elliottii and Schima superba were chosen as representative needle-leaved and broad-leaved tree species. Approximately $10 \mathrm{~g}$ of leaf litter of one species was spread evenly in a 20 $\mathrm{cm} \times 20 \mathrm{~cm}$ mesh litter bag with a 2.540-mm mesh upper surface and a $0.635-\mathrm{mm}$ mesh lower surface. The bags were placed at locations adjacent to foliage collection sites in a P. elliottii plantation with 20 $\mathrm{m} \times 20 \mathrm{~m}$ spacing or a $S$. superba plantation with $15 \mathrm{~m} \times 15 \mathrm{~m}$ spacing in March 2013. The leaf litter 
was allowed to decompose in the field for different periods of time $(0,2,5,8$, and 12 months). After degradation, samples were gently rinsed with Milli-Q water, air-dried, and cut into 0.5 -cm pieces. DOM was extracted from the decomposed litter by mixing litter and Milli-Q water at a litter to water ratio of 1:10 (m/v). This mixture was shaken for $24 \mathrm{~h}$ at $200 \mathrm{rpm}$ on a horizontal rotator, centrifuged for $15 \mathrm{~min}$ at $8000 \mathrm{rpm}$ at $4{ }^{\circ} \mathrm{C}$, and then filtered through a $0.2-\mu \mathrm{m}$ cellulose acetate membrane

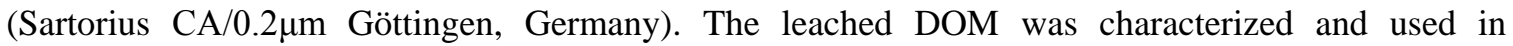
degradation experiments within one week [41, 42]. Additionally, the concentrations of the 15 congeners of PAHs in the DOM were detected in a preliminary study (Fig S11) and they were proved too low to affect the phenanthrene degradation efficiency discussed in this current study.

\subsection{Experimental approach}

Three substudies were carried out to determine the effects of DOM with different properties and concentrations on the degradation of phenanthrene by Phe- 1 and to investigate the mechanisms of these effects.

\subsubsection{Influence of litter species, decomposition time, and DOM concentration on degradation of phenanthrene}

DOM derived from P. elliottii (PD) and S. superba (SD) leaf litter that had decomposed in the field

for $0,2,5,8$, or 12 months was used in a phenanthrene degradation experiment. The experiment was performed with 30-mL mixture of minimal medium (MM) containing DOM (SD at 0, 50, 100, 200, and $400 \mathrm{mg} / \mathrm{L}$; PD at $0,50,100 \mathrm{mg} / \mathrm{L})$, the strain Phe- $1\left(10^{9}\right.$ cells $\left./ \mathrm{mL}\right)$ and $100 \mathrm{mg} / \mathrm{L}$ phenanthrene in a 50-mL Erlenmeyer flask with a permeable silica gel stopper (phenanthrene dissolved in hexane was 
first added to the dry flask, and then MM was added after the hexane had completely vaporized). The suspension was incubated at $35{ }^{\circ} \mathrm{C}$ on an orbital shaker (THZ-C, Guangzhou, China) operating at 160 rpm for $36 \mathrm{~h}$, after which the residual phenanthrene was extracted by methylene chloride and measured by GC-MS. Treatment setting is in Table.1.

For each species and litter decomposition time, the DOM concentration $(100 \mathrm{mg} / \mathrm{L})$ that had a greatest promoting effect on phenanthrene degradation was used in a second series of degradation experiments under the conditions described above. The growth (OD600) and catechol 2,3-dioxygenase (C23O) activity of Phe-1were measured.

\subsubsection{Mechanisms of DOM influence on phenanthrene degradation}

DOM derived from P. elliottii (PD) and S. superba (SD) leaf litter that had decomposed in the field for $0,2,5,8$, or 12 months was used at the concentration of $100 \mathrm{mg} / \mathrm{L}$. Controls that lacked either phenanthrene (DP1) or Phe-1 cells (DP) were set. At the end of the degradation experiment (the incubation conditions were identical to those in 2.5.1), DOM composition was characterized by EEMs-FRI and $\mathrm{pH}$ was determined.

Using the DOM that had exhibited the best phenanthrene degradation performance in previous experiments (P12), another series of degradation experiments was carried out by setting P12 at different concentrations of $0,1,50,100$, and $200 \mathrm{mg} / \mathrm{L}$. The incubation conditions were identical to those in 2.5.1. Outcomes measured were solubility and percent degradation of phenanthrene, and growth (OD600) and C23O activity of Phe-1. 


\subsubsection{Degradation time course of phenanthrene in the presence of DOM}

A phenanthrene degradation time course experiment with incubation conditions identical to those in 2.5.1 was carried out using P12 at a concentration of $100 \mathrm{mg} / \mathrm{L}$ under the conditions described above (2.5.1), with controls that lacked either phenanthrene (DP1) or DOM (PP). Percent degradation of phenanthrene, $\mathrm{pH}$, and Phe- 1 growth and $\mathrm{C} 23 \mathrm{O}$ activity were determined at incubation times of 0 , 12, 24, and $36 \mathrm{~h}$. In addition, composition of DOM composition before and after degradation was analyzed by EEMs-FRI.

\subsection{Analytical methods}

OD600 and C23O activity of Phe-1 were measured by Shimadzu UV-Vis spectrophotometer (Shimadzu UV-1800 Kyoto, Japan) by following methods described in literatures [43, 44], with minor modification by setting the change rate of absorbance at $375 \mathrm{~nm}$ (A '375) which represent the $\mathrm{C} 23 \mathrm{O}$ activity, A '375=(A $\left.A_{2}-A_{1}\right) / A_{1}$. Dissolved organic carbon (DOC) was measured using a TOC-VCSH analyzer (Shimadzu ON-LINE TOC-VCSH Kyoto, Japan). Composition of DOM was analyzed by EEMs-FRI. Fluorescence EEM measurements were conducted with a fluorescence spectrophotometer (Aqualog-UV-800, Horiba, USA), which used a xenon excitation source with slits set to $5 \mathrm{~nm}$ for both excitation and emission. The excitation wavelengths were set from 200 to $400 \mathrm{~nm}$ in 5 -nm increments, and the emission wavelengths were detected from 290 to $500 \mathrm{~nm}$ in 2-nm steps [41]. All samples were acidified to $\mathrm{pH} 3$ with $\mathrm{HCl}$ and diluted to a final $\mathrm{DOC}$ concentration of $10 \mathrm{mg} / \mathrm{L}$. Residual phenanthrene was measured by a gas chromatograph (Thermo-Ultra Trace GC-DSQ Massachusetts, USA) equipped with a mass spectroscopy detector with a quadrupole analyzer. Briefly, cultivating 
culture derived at the end of the degradation were put into a $60 \mathrm{~mL}$ separatory funnel and the $50 \mathrm{~mL}$ Erlenmeyer flask used for cultivation was washed by $7 \mathrm{~mL}$ methylene chloride three times to guarantee the phenanthrene left in the Erlenmeyer flask is fully taken into the separatory funnel (the samples were spiked with $2 \mathrm{mg} / \mathrm{L}$ phenanthrene-d10 to determine the phenanthrene recovery rate). Subsequent extraction, purification and detection on GC-MS were conducted according to literature [45].

\subsection{Statistical methods}

Phenanthrene concentrations were quantified using M-terphenyl as an internal standard and adjusted based on the recovery rate of phenanthrene-d10, after which the phenanthrene degradation rate (percent) was calculated. Analysis of variance (ANOVA) was performed to determine whether DOM source, concentration, incubation time, and DOM composition before or after degradation significantly affected phenanthrene degradation. Correlation analysis was performed to measure correlation between the phenanthrene degradation rate and $\mathrm{pH}$, growth and $\mathrm{C} 23 \mathrm{O}$ activity of Phe-1, and DOM composition. Correlation coefficients were calculated using Spearman's correlation. ANOVA and correlation were conducted using SPSS 17.0 [46], and figures were drawn using OriginPro8.0 [47]. Robability levels of $\mathrm{P}<0.05$ and $\mathrm{P}<0.01$ were regarded as statistically significant [46]. 


\section{Results and discussion}

\subsection{Influence of litter species, and litter composition time and DOM concentration on degradation of phenanthrene}

\subsubsection{Litter species}

Organic carbon plays a key role in the environmental fate of PAHs [48]. DOM released from forest leaf litter is an important source of organic carbon in the forest system and can be utilized by microorganisms that degrade PAHs. In the study, the DOM derived from P. elliottii and S. superba leaf litter allowed to be decomposed in the field for $0,2,5,8$, and 12 months promoted faster phenanthrene degradation compared to the control after $36 \mathrm{~h}$ of incubation (Fig. 1a and 1b). The DOM derived from P. elliottii leaf litter (PD) increased phenanthrene degradation by $8.0-16.9 \%$, which were generally more than $10 \%$ except that in P8 (8.0\% in $100 \mathrm{mg} / \mathrm{L}$, Fig.1b). Meanwhile, the promoting effect of DOM derived from S. superba leaf litter (SD) was 1.1-9.7 \% (Fig.1a).

The added DOM also enhanced the biological activity of Phe-1, increasing growth and expression of catechol 2,3-dioxygenase (C23O), an enzyme necessary for phenanthrene degradation (Fig. 1c and 1d). DOM also promoted growth and catechol 2,3-dioxygenase activity of the Phe-1 strain (Fig. 1c and 1d). Again, these effects were greater for PD than for SD, which may explain why the former was more effective at promoting phenanthrene degradation. Phenanthrene is cleaved and converted to 1-hydroxy-2-naphthoic acid by catalyzed dioxygenase, after which it divides into two metabolic pathways, one leading to phthalic acid and the other leading to salicylic acid, back to catechol, and then to gentisate before mineralization to water and carbon dioxide [49-51]. Of the two 
catechol degradation enzymes catechol 2,3-dioxygenase (C23O) and catechol 1,2-dioxygenase (C12O), only the former showed activity in Phe-1, indicating that the $\mathrm{C} 23 \mathrm{O}$ pathway was used. Therefore, $\mathrm{C} 23 \mathrm{O}$ activity during phenanthrene degradation was used as an index of biological activity of the Phe-1 strain. Growth of Phe-1 was higher in the DPP treatment (DOM+phenanthrene+Phe-1) compared to the DP1 and PP treatments, showing that DOM and phenanthrene act synergistically to promote the growth of Phe-1 (Fig. 1c).

\subsubsection{Litter decomposition time}

The results described above showed that DOM increased the degradation rate of phenanthrene.

To investigate the changes in DOM during the decomposition time, the EEMs-FRI method was used.

Chen (2003)[38] operationally defined five EEM zones such that peaks in different zones represent different types of material. Peaks in zones 1 and 2 indicate the presence of simple aromatic amino acids such as tyrosine[52], peaks in zone 3 indicate fulvic acid-like material (FA-like), peaks in zone 4 are associated with soluble microbial byproduct-like material, and peaks in zone 5 indicate humic acid-like (HA-like) material (Fig. S3).

In the present study, the composition and material of DOM derived from litter that had decomposed for 12 months in the field changed as litter decomposition time increased (Fig.S4a and S5a) as expected. EEM zones 1, 2, and 4 decreased and zones 3 and 5 increased as the leaf litter decomposed, increasing the proportion of HA-like material. Moreover, our previous studies have shown that the degree of aromatization and the molecular weight of DOM increased as litter decomposition time is extended (Fig.S4b, 4c and S5a, 5c). The specific ultraviolet absorbance of SD 
at $254 \mathrm{~nm}$ (SUV-A254) and $280 \mathrm{~nm}$ (SUV-A280) increased with decomposition time, which is evidence of an increase in the aromaticity of DOM (Fig.S4b).

The decomposition time significantly affected the degradation rate for SD but not for PD (Fig. 1a and $1 \mathrm{~b}$ ), and the treatment combination that was most effective was $P$. elliottii-derived DOM (PD) prepared from litter that had decomposed for 12 months (P12) and used at a concentration of 100 mg/L, which enhanced the degradation rate by $16.9 \%$ (Fig. 1b). For the S. superba-derived DOM (SD), the best results were also obtained with a litter decomposition time of 12 months (S12) and a SD concentration of $100 \mathrm{mg} / \mathrm{L}$, which enhanced the degradation rate by $9.7 \%$ (Fig. 1a). This effect may have been due to humic materials, because the HA and FA content of the DOM increased as litter decomposition time was extended, while the content of simple proteins and tyrosine decreased (Fig.S4a and S5a). Hur et al. showed that after 90 days of leaf decomposition, the aromaticity of extracted DOM increased and polar components decreased, enhancing nonlinear binding sites that could bind with hydrophobic organic contaminants (HOC), and that microbial changes in DOM may make hydrophobic structures more accessible to phenanthrene, with the result that microorganisms preferentially attack relatively hydrophilic structures of DOM exposed to the aqueous phase [53, 54]. Han et al. demonstrated that residual PAH concentrations in soil were lower after addition of DOM derived from mushroom cultivation substrate waste (MCSW) or DOM derived from cow manure (CM) than after addition of DOM derived from wheat stalks (WS) due to the higher proportion of the hydrophobic fraction in DOM-MCSW and DOM-CM than in DOM-WS[2]. 


\subsubsection{DOM concentrations}

The phenanthrene degradation experiment utilizing P12 at different concentrations confirmed that P12 can promote phenanthrene degradation (Fig. 2c) as well as the growth (Fig. 2e) and C23O activity (Fig. 2f) of Phe-1, as was reported above. It also demonstrated that P12 can enhance the solubility of phenanthrene (Fig. 2d). However, it is noteworthy that the curves showing the relationship of these four dependent variables on P12 concentration all had maxima, below which P12 had a promotion effect and above which it had an inhibitory effect (Figs. 2c, 2d, 2e, and 2f). It is possible that low pH or carbon competition between phenanthrene and DOM inhibited C23O activity of Phe-1 (Fig.S7 in P8 and S10 in 200mg/L). Phenanthrene solubility and C23O activity of Phe-1 were highest at an S12 concentration of $50 \mathrm{mg} / \mathrm{L}$, but the phenanthrene degradation rate and growth of Phe-1 were highest at $100 \mathrm{mg} / \mathrm{L}$.

\subsection{Mechanisms of DOM influence on phenanthrene degradation}

\subsubsection{The changes in DOM composition after degradation of phenanthrene}

The results described above showed that DOM could enhance the degradation of phenanthrene

by promoting the growth and $\mathrm{C} 23 \mathrm{O}$ activity of Phe-1 strain and enhancing the solubility of phenanthrene. To investigate the mechanisms by which fractions of DOM influence the degradation of phenanthrene, DOM derived from leaf litter was used in degradation experiments at a concentration of $100 \mathrm{mg} / \mathrm{L}$ (Fig.S7 and S8). The results of P12, which was the DOM with the greatest degradation promoting effect, are shown in Fig.2a and 2b.

After $36 \mathrm{~h}$ of incubation, zones 3 and 5 decreased in the DP treatment (DOM+phenanthrene) that 
lacked Phe-1; zones 1, 2, and 4 decreased in the DP1 treatment (DOM+Phe-1) that lacked phenanthrene; and zones 4 and 5 decreased in the DPP treatment (Fig. 2a). These changes in the composition of DOM provide evidence that the proteins and tyrosine of DOM were used by the strain Phe-1, and that FA and HA in the DOM bound with phenanthrene (then filtered by $0.2-\mu \mathrm{m}$ cellulose acetate membrane (CA), resulting in decreasing). The $\mathrm{pH}$ observed at the end of the experiment differed between treatments, confirming the EEMs-FRI results (Fig. 2b). During phenanthrene degradation, the $\mathrm{pH}$ in the DPP and DP treatments declined due to the HA and FA that remained after utilization of proteins and tyrosine for microbial growth. In addition, HA was co-metabolized during phenanthrene degradation in the DPP treatment (Fig. 2a) (phenanthrene was not detected on CA, thus, the HA would not be filtered) and since the $\mathrm{pH}$ of FA is lower than that of HA, the post-incubation $\mathrm{pH}$ was lower in the DPP treatment than in the DP1 treatment (Fig. 2b).

We suggest that the proteins and tyrosine of DOM are readily available carbon and nitrogen sources that support growth and $\mathrm{C} 23 \mathrm{O}$ expression of Phe-1, and that FA and HA formed complexes with phenanthrene that increased its availability, both of which enhanced the phenanthrene degradation rate. The use of amendments to enhance the degradation of HOCs has been reported previously. Adding peptone, glucose, and yeast extracts increased the rate of microbial degradation of phenanthrene [55], and low-molecular-weight organic acids (LMWOAs), Tween-80, FA improved the bioavailability of PAHs (pyrene and phenanthrene) and increased the degradation rate[18, 56, 57]. Lu (2011) [10] reported that the addition of gaseous toluene as a co-substrate promoted the growth of degrading bacteria and improved degradation enzyme activity, thereby promoting phenanthrene 
degradation. Han (2015) [2] showed that DOM derived from agricultural wastes enhanced the mobility of PAHs and increased nutrient levels for indigenous soil microorganisms.

\subsubsection{Degradation time course of phenanthrene in the presence of DOM}

The results described above show that the FA and HA of DOM increased the bioavailability of phenanthrene and the proteins and tyrosine of DOM promoted the biological activity of Phe-1. However, which of the abovementioned processes came first was not yet determined. In a phenanthrene degradation time course experiment carried out in the presence of $100 \mathrm{mg} / \mathrm{L} \mathrm{P} 12$, both the phenanthrene degradation rate and growth of Phe-1 were higher in the DPP treatment compared to the PP control at the 12-h time point (Fig. 3a and 3b), indicating that DOM can simultaneously promote Phe-1 growth and phenanthrene availability. Moreover, the sustained high growth between the 12-h and 24-h time points exhibited by Phe-1 in the DPP treatment compared to the DP1 and PP controls (Fig. 3b) implies that other DOM fractions besides proteins and tyrosine can support Phe-1 growth. In addition, the presence of DOM shortened the degradation time from $48 \mathrm{~h}$ to $24 \mathrm{~h}$ (Fig. $3 \mathrm{a}$, Fig.S1). Changes in the composition of DOM during the course of phenanthrene degradation were similar to those described above. At $12 \mathrm{~h}$, zones 1, 2, and 4 decreased in the DP1 treatment (Fig. 3d) and zones 2, 4, and 5 decreased in the DPP treatment (Fig. 3e). For the latter treatment, zone 5 decreased at $24 \mathrm{~h}$ and $36 \mathrm{~h}$ mainly (Fig. 3e).

In the current study, we also found that HA and FA in the DOM could not be utilized by the degrading bacteria in the absence of phenanthrene, but HA could be utilized when phenanthrene was present (Fig. 2a). Based on the EEMs-FRI results (Fig. 2a), we speculate that early in the course of 
degradation (Fig. 3e), HA and FA acted as carriers, complexing with phenanthrene and increasing its availability to Phe-1. By the 12-h time point, the FA will have lost its phenanthrene and the HA will be filtered, and between 12 and 24 h HA will be co-metabolized with phenanthrene. The observed changes in $\mathrm{pH}$ (Fig. $2 \mathrm{~b}$ and $3 \mathrm{f}$ ) confirmed the results of EEMs-FRI. Post-degradation, the $\mathrm{pH}$ in the DPP and DP1 treatments had declined due to the presence of residual HA and FA after microbial utilization of DOM proteins and tyrosine. In addition, HA was co-metabolized in the DPP treatment, and since the $\mathrm{pH}$ of FA is lower than that of HA, the $\mathrm{pH}$ was lower in the DPP compared to the DP1 treatment (Fig. 2b). As shown in Fig. 3f, the pH of both DPP and DP1 declined between $0 \mathrm{~h}$ and $12 \mathrm{~h}$, with DPP having a steeper decline. The observed changes in the phenanthrene degradation rate and in Phe-1 biomass over time are additional evidence of co-metabolism of HA. There was little change in the population size of Phe-1 (Fig. 3b) or in the composition of DOM (Fig. 3d) after $12 \mathrm{~h}$ in the DP1 treatment because the proteins and tyrosine of DOM were used up, but in the DPP treatment the phenanthrene degradation rate (Fig. 3a) and the biomass of Phe-1 (Fig. 3b) kept increasing after $12 \mathrm{~h}$, and a faster rate than in the PP treatment, indicating that there were substrates other than phenanthrene or the proteins and tyrosine of DOM that were stimulating growth of Phe-1.This is a surprising finding of this study that the HA of DOM could be co-metabolized during phenanthrene degradation.

\subsubsection{Interacting mechanisms in the DOM-phenanthrene-microorganism system}

Much research has been conducted on the degradation of phenanthrene. Some authors have suggested that microorganisms are able to degrade only dissolved PAHs, and that addition of DOM 
decreases the bioavailability of PAHs $[25,26]$. Other researchers have concluded that PAHs bound to DOM are accessible to bacteria and can be degraded as rapidly as PAHs in the liquid phase $[21,23$, 27].

DOM can form complexes with PAHs by $\mathrm{NH}-\pi$ and $\pi-\pi$ interactions and via hydrophobic and micellar effects, thereby affecting the bioavailability (solubility and diffusive mass transfer) and toxicity of PAHs $[9,24,33]$. DOM, supplied as nutrients, could enhance the biological activity and the uptake rate of bacterium as well $[22,29]$. In the present research, the addition of DOM derived from leaf litter significantly hastened the degradation of phenanthrene (Fig. 1a and 1b), and the time of degradation was shortened from $48 \mathrm{~h}$ to $24 \mathrm{~h}$ (Fig. 3a and Fig. S1). The growth (Fig. 1c, 2e and 3b) and the biological activity (biomass and $\mathrm{C} 23 \mathrm{O}$ activity) of Phe-1 (Fig. 1d, 2f and 3c) were increased in the presence of DOM because the proteins and tyrosine of DOM (Fig. 2a) served as sources of readily available carbon and nitrogen for Phe-1 growth before $12 \mathrm{~h}$ (Fig.3b, 3d). The HA and FA of DOM (with more hydrophobic structures more accessible to phenanthrene) affected the fate of phenanthrene primarily by combining with it and increasing its bioavailability at the beginning (Fig. 2a, 2d). Both of that effect acted at the same time. At $12 \mathrm{~h}$, the FA have lost its phenanthrene and the HA will be co-metabolized and further stimulate phenanthrene degradation (Fig.3a, 3b, 3e).

The observed enhancement of phenanthrene degradation could not be explained solely by improved phenanthrene solubility or by the more rapid uptake of phenanthrene by Phe-1 cells. A DOM concentration of $50 \mathrm{mg} / \mathrm{L}$ resulted in the highest levels of phenanthrene solubility (Fig. 2d) and C23O activity (Fig. 2f), but the highest degradation rate was observed in the $100 \mathrm{mg} / \mathrm{L}$ treatment (Fig. 
2c). The solubility of phenanthrene was lower in the $100 \mathrm{mg} / \mathrm{L}$ DOM treatment than in the control treatment without DOM (means more absorbed phenanthrene in 100mg/L treatment) (Fig. 2d), which could be explained by the fact that the addition of DOM can reduce substrate concentrations at the surface of microbial cells by enhancing the uptake rate of dissolved compounds and the mass transfer of PAHs on the one hand [58]. On the other hand, the strain phe- 1 could use the bound phenanthrene directly. For example, HA (a form of DOM ) which has been described with a micellar microstructure similar to that of surfactants, can incorporate dissolved PAHs [12], and a fraction of micellar-phase PAHs is directly bioavailable to cells and does not need to be dissolved in the liquid phase [59]. DOM with many hydrophobic and nonpolar components may be more effective for biodegradation of PAHs because degrading bacteria can access to the incorporated DOM-PAHs directly, and the bioavailability of DOM-PAHs is higher than that of dissolved PAHs [2, 22, 32]. What is more, HA can transport phenanthrene towards the degrading bacteria as well, which enhances their ability to take up both dissolved and bound PAHs [60, 61].

These results suggest that DOM enhanced phenanthrene bioavailability by increasing the solubility and mass transfer of phenanthrene, enhancing the biological activity and the uptake kinetics of Phe-1, and increasing the bacterium's direct access to DOM-bound phenanthrene.

\section{Conclusions}

In conclusion, we investigated the effects of DOM derived from the leaf litter of two tree species

(Pinus elliottii as needle-leaved species and Schima superba as and broad-leaved species) on 
microbial degradation of phenanthrene. We found that DOM promoted the degradation of phenanthrene through simultaneous promoting effects on phenanthrene bioavailability and on the biological activity of the bacterium Sphingobium sp. Phe-1. Readily available carbon and nitrogen sources in DOM (such as protein and tyrosine) supported growth of Phe-1 and increased the activity of catechol 2,3-dioxygenase, an enzyme in the phenanthrene degradation pathway. FA (fulvic acid) and HA (humic acid) in the DOM absorbed phenanthrene, enhancing its mobility while allowing the bacteria directly access to DOM-bound phenanthrene. HA was co-metabolized by Phe-1, which further stimulated phenanthrene degradation.

\section{Acknowledgements}

Support for this study was provided by National Science Foundation for Distinguished Young Scholars of China (No.41225004), Natural Science Foundation of China (No.41001322), and Fundamental Research Funds for the Central Universities (11lgpy98).

\section{Suplementary material}

Additional figures and table show measurement data from this study.

\section{References}

[1] A.K. Haritash, C.P. Kaushik, Biodegradation aspects of Polycyclic Aromatic Hydrocarbons (PAHs): A review, J. Hazard. Mater, 169 (2009) 1-15.

[2] X.M. Han, Y.R. Liu, L.M. Zhang, J.Z. He, Insight into the Modulation of Dissolved Organic Matter on Microbial Remediation of PAH-Contaminated Soils, Microb. Ecol., 70 (2015) 400-410.

[3] M. Howsam, K.C. Jones, P. Ineson, Dynamics of PAH deposition, cycling and storage in a 
mixed-deciduous (Quercus-Fraxinus) woodland ecosystem, Environ. Pollut, 113 (2001) 163-176.

[4] C.A. Belis, I. Offenthaler, P. Weiss, Semivolatiles in the Forest Environment: The Case of PAHs, in: P. Schröder, D.C. Collins (Eds.) Organic Xenobiotics and Plants: From Mode of Action to Ecophysiology, Springer Netherlands, Dordrecht, 2011, pp. 47-73.

[5] E. Brorström-Lundén, C. Löfgren, Atmospheric fluxes of persistent semivolatile organic pollutants to a forest ecological system at the Swedish west coast and accumulation in spruce needles, Environ. Pollut, 102 (1998) 139-149.

[6] M. Horstmann, M.S. McLachlan, Atmospheric deposition of semivolatile organic compounds to two forest canopies, Atmos. Environ, 32 (1998) 1799-1809.

[7] J.B Huang, Distribution and absorption of polycyclic aromatic hydrocarbons in tipical forest soil of Guangzhou, Magisterial Thesis, Chinese Academy of Forestry, China, 2013.

[8] X.A Zhao, Study on distribution behavior characteristic of PAHs in the forest soil and plant leaves, Doctorial Thesis, Yanbian University, China, 2016.

[9] Y. Yang, N. Zhang, M. Xue, S.T. Lu, S. Tao, Effects of soil organic matter on the development of the microbial polycyclic aromatic hydrocarbons (PAHs) degradation potentials, Environ. Pollut, 159 (2011) 591-595.

[10] X.Y. Lu, T. Zhang, H.H.P. Fang, Bacteria-mediated PAH degradation in soil and sediment, Appl. Microbiol. Biotechnol., 89 (2011) 1357-1371.

[11] A. Gottfried, N. Singhal, R. Elliot, S. Swift, The role of salicylate and biosurfactant in inducing phenanthrene degradation in batch soil slurries, Appl. Microbiol. Biotechnol., 86 (2010) 1563-1571.

[12] M.C. Tejeda-Agredano, P. Mayer, J.J. Ortega-Calvo, The effect of humic acids on biodegradation of polycyclic aromatic hydrocarbons depends on the exposure regime, Environ. Pollut, 184 (2014) 435-442.

[13] G. Bengtsson, P. Zerhouni, Effects of carbon substrate enrichment and DOC concentration on biodegradation of PAHs in soil, J. Appl. Microbiol., 94 (2003) 608-617. 
[14] R. van Herwijnen, B. Joffe, A. Ryngaert, M. Hausner, D. Springael, H.A.J. Govers, S. Wuertz, J.R. Parsons, Effect of bioaugmentation and supplementary carbon sources on degradation of polycyclic aromatic hydrocarbons by a soil-derived culture, Fems Microbiol. Ecol, 55 (2006) 122-135.

[15] K.E. Smith, M. Thullner, L.Y. Wick, H. Harms, Sorption to humic acids enhances polycyclic aromatic hydrocarbon biodegradation, Environ. Sci. Technol, 43 (2009) 7205-7211.

[16] T. Hadibarata, S. Tachibana, K. Itoh, Biodegradation of chrysene, an aromatic hydrocarbon by Polyporus sp. S133 in liquid medium, J. Hazard. Materials, 164 (2009) 911-917.

[17] M. Pichler, G. Guggenberger, R. Hartmann, W. Zech, Polycyclic aromatic hydrocarbons (PAH) in different forest humus types, Environ. Sci. Pollut. Res, 3 (1996) 24-31.

[18] W. Ling, L. Ren, Y. Gao, X. Zhu, B. Sun, Impact of low-molecular-weight organic acids on the availability of phenanthrene and pyrene in soil, Soil Biol. Biochem, 41 (2009) 2187-2195.

[19] S. Lesage, H. Xu, K. Novakowski, S. Brown, L. Durham, Use of humic acids to enhance the removal of aromatic hydrocarbons from contaminated aquifers. Part II: Pilot scale, in: Proceedings of the $5^{\text {th }}$ annual symposium on groundwater and soil remediation, 1995.

[20] L.M. Carmichael, F.K. Pfaender, The effect of inorganic and organic supplements on the microbial degradation of phenanthrene and pyrene in soils, Biodegradation, 8 (1997) 1-13.

[21] J.J. Ortega-Calvo, C. Saiz-Jimenez, Effect of humic fractions and clay on biodegradation of phenanthrene by a Pseudomonas fluorescens strain isolated from soil, Appl. environ. microbiol, 64 (1998) 3123-3126.

[22] J.J. Haftka, J.R. Parsons, H.A. Govers, J.J. Ortega - Calvo, Enhanced kinetics of solid - phase microextraction and biodegradation of polycyclic aromatic hydrocarbons in the presence of dissolved organic matter, Environ. Toxicol. Chem, 27 (2008) 1526-1532.

[23] Y. Laor, P.F. Strom, W.J. Farmer, Bioavailability of phenanthrene sorbed to mineral-associated humic acid, Water Res, 33 (1999) 1719-1729.

[24] X. Zhan, W. Wu, L. Zhou, J. Liang, T. Jiang, Interactive effect of dissolved organic matter and phenanthrene on soil enzymatic activities, Journal of Environmental Sciences, 22 (2010) 
607-614.

[25] T.N.P. Bosma, P.J.M. Middeldorp, G. Schraa, A.J.B. Zehnder, Mass Transfer Limitation of Biotransformation: Quantifying Bioavailability, Environ. Sci. Technol, 31 (1997) 248-252.

[26] J. Akkanen, J.V. Kukkonen, Measuring the bioavailability of two hydrophobic organic compounds in the presence of dissolved organic matter, Environ. Toxicol. Chem, 22 (2003) 518-524.

[27] D. Vacca, W. Bleam, W. Hickey, Isolation of soil bacteria adapted to degrade humic acid-sorbed phenanthrene, Appl. Environ. Microbiol, 71 (2005) 3797-3805.

[28] A. Haderlein, R. Legros, B. Ramsay, Enhancing pyrene mineralization in contaminated soil by the addition of humic acids or composted contaminated soil, Appl. Microbiol. Biotechnol., 56 (2001) 555-559.

[29] K.Y. Cheng, J.W.C. Wong, Combined effect of nonionic surfactant Tween 80 and DOM on the behaviors of PAHs in soil-water system, Chemosphere, 62 (2006) 1907-1916.

[30] H. Yu, G.H. Huang, C.J. An, J. Wei, Combined effects of DOM extracted from site soil/compost and biosurfactant on the sorption and desorption of PAHs in a soil-water system, J. Hazard. Mater, 190 (2011) 883-890.

[31] Y. Mei, F. Wu, L. Wang, Y. Bai, W. Li, H. Liao, Binding characteristics of perylene, phenanthrene and anthracene to different DOM fractions from lake water, J. Environ. Sci, 21 (2009) 414-423.

[32] M.C. Tejeda-Agredano, P. Mayer, J.J. Ortega-Calvo, The effect of humic acids on biodegradation of polycyclic aromatic hydrocarbons depends on the exposure regime, Environ. Pollut, 184 (2014) 435-442.

[33] C. Plaza, B. Xing, J.M. Fernández, N. Senesi, A. Polo, Binding of polycyclic aromatic hydrocarbons by humic acids formed during composting, Environ. Pollut, 157 (2009) 257-263.

[34] T. Toyama, T. Furukawa, N. Maeda, D. Inoue, K. Sei, K. Mori, S. Kikuchi, M. Ike, Accelerated biodegradation of pyrene and benzo[a]pyrene in the Phragmites australis rhizosphere by bacteria-root exudate interactions, Water Res, 45 (2011) 1629-1638. 
[35] H. Yi, D.E. Crowley, Biostimulation of PAH Degradation with Plants Containing High Concentrations of Linoleic Acid, Environ. Sci. Technol, 41 (2007) 4382-4388.

[36] L. Meng, Y.G. Zhu, Pyrene Biodegradation in an Industrial Soil Exposed to Simulated Rhizodeposition: How Does It Affect Functional Microbial Abundance?, Environ. Sci. Technol, 45 (2011) 1579-1585.

[37] B.C. Martin, S.J. George, C.A. Price, M.H. Ryan, M. Tibbett, The role of root exuded low molecular weight organic anions in facilitating petroleum hydrocarbon degradation: Current knowledge and future directions, Sci. Total Environ, 472 (2014) 642-653.

[38] W. Chen, P. Westerhoff, J.A. Leenheer, K. Booksh, Fluorescence excitation - Emission matrix regional integration to quantify spectra for dissolved organic matter, Environ. Sci. Technol, 37 (2003) 5701-5710.

[39] Z.D. Chen, Isolation identification of a Pyrene- degrading bacteri $\mu \mathrm{m}$ and cloning of catechol-2, 3-dioxygenase gene and expression, Magisterial Thesis, Xinjiang University, China, 2013.

[40] K. Masakorala, J. Yao, M. Cai, R. Chandankere, H. Yuan, H. Chen, Isolation and characterization of a novel phenanthrene (PHE) degrading strain Psuedomonas sp. USTB-RU from petroleum contaminated soil, J. Hazard. Mater, 263 (2013) 493-500.

[41] Q. Jian, T.H. Boyer, X. Yang, B. Xia, X. Yang, Characteristics and DBP formation of dissolved organic matter from leachates of fresh and aged leaf litter, Chemosphere, 152 (2016) 335-344.

[42] D. Cai , X.H. Yang, Q.S. Lei, S.Z. Wang, R.L. Qiu, Y.H. Yang. Filed decomposition and DOM release dynamics of typical trees leaf litter in south china. Chin. J. Appl. Ecol, 27 (2016) 1-10. [43] H.B.Sun. Isolation, identification and characteristics of PAHs- degrading bacteria and preliminary study on catechol 2, 3-dioxygenase, Magisterial Thesis, Shandong University, China, 2009.

[44] G.U. Hupert-Kocurek K, Wojcieszynska D, Characterization of catechol 2, 3-dioxygenase from Planococcus sp. strain S5 induced by high phenol concentration, Acta Biochimica Polonica, 59 (2012) 345-351. 
[45] Q.S Lei, X.H Yang, Z.W Fang, S.Z Wang, Y Zhao, R.L Qiu, Characteristics of fresh leaf litter-derived dissolved organic matter and its capacity to enhance the apparent water solubility of phenanthrene. Ecol. Environ. Sci, 23(2014) 170-177.

[46] Q. Lin, S. Chen, Y. Chao, X. Huang, S. Wang, R. Qiu, Carboxylesterase-involved metabolism of di-n-butyl phthalate in pumpkin (Cucurbita moschata) seedlings, Environ. Pollut,(2016)1-10.

[47] R.M. Li, graphic Origin 8.0 Scientific Graphing and Data Analysis (Paperback)(Chinese Edition), in: X.M. Wu (Ed.), Posts Telecom Press, Beijing, 2009, pp. 81-133.

[48] J.J. Ortega-Calvo, M.C. Tejeda-Agredano, C. Jimenez-Sanchez, E. Congiu, R. Sungthong, J.L. Niqui-Arroyo, M. Cantos, Is it possible to increase bioavailability but not environmental risk of PAHs in bioremediation?, J. Hazard. Mater, 261 (2013) 733-745.

[49] T. Hadibarata, S. Tachibana, Characterization of phenanthrene degradation by strain Polyporus sp. S133, J. Environ. Sci, 22 (2010) 142-149.

[50] F. Moscoso, F.J. Deive, M.A. Longo, M.A. Sanromán, Technoeconomic assessment of phenanthrene degradation by Pseudomonas stutzeri CECT 930 in a batch bioreactor, Bioresour. Technol, 104 (2012) 81-89.

[51] S. Gao, J.S. Seo, J. Wang, Y.S. Keum, J. Li, Q.X. Li, Multiple degradation pathways of phenanthrene by Stenotrophomonas maltophilia C6, International Biodeterior. Biodegrad, 79 (2013) 98-104.

[52] W. James L., George R.A., Brian A., Bergamaschi, Miranda S.F., Roger F.J., Mopper K.,, Evaluation of Specific UltravioletAbsorbance as an Indicator of the Chemical Composition and Reactivity of Dissolved Organic Carbon, Environ. Sci. Technol, 37 (2003) 4702-4708.

[53] P.M.H. Hur J., Mark A., Schlautman*, Microbial Transformation of Dissolved Leaf Litter Organic Matter and Its Effects on Selected Organic Matter Operational Descriptors, Environ. Sci. Technol, 43 (2009) 2315-2321.

[54] J. Hur, B.M. Lee, H.S. Shin, Microbial degradation of dissolved organic matter (DOM) and its influence on phenanthrene-DOM interactions, Chemosphere, 85 (2011) 1360-1367.

[55] H.P. Zhao, L. Wang, J.R. Ren, Z. Li, M. Li, H.W. Gao, Isolation and characterization of 
phenanthrene-degrading strains Sphingomonas sp. ZP1 and Tistrella sp. ZP5, J. Hazard. Mater, 152 (2008) 1293-1300.

[56] K. Chen, Q. Zhu, Y. Qian, Y. Song, J. Yao, M.M.F. Choi, Microcalorimetric investigation of the effect of non-ionic surfactant on biodegradation of pyrene by PAH-degrading bacteria Burkholderia cepacia, Ecotoxicol. Environ. Saf, 98 (2013) 361-367.

[57] B.W. Bogan, W.R. Sullivan, Physicochemical soil parameters affecting sequestration and mycobacterial biodegradation of polycyclic aromatic hydrocarbons in soil, Chemosphere, 52 (2003) 1717-1726.

[58] J.J.H. Haftka, J.R. Parsons, H.A.J. Govers, J.J. Ortega-Calvo, Enhanced kinetics of solid-phase microextraction and biodegradation of polycyclic aromatic hydrocarbons in the presence of dissolved organic matter, Environ. Toxicol. Chem, 27 (2008) 1526-1532.

[59] D.G. Brown, Relationship between Micellar and Hemi-Micellar Processes and the Bioavailability of Surfactant-Solubilized Hydrophobic Organic Compounds, Environ. Sci. Technol, 41 (2007) 1194-1199.

[60] K.E.C. Smith, M. Thullner, L.Y. Wick, H. Harms, Sorption to Humic Acids Enhances Polycyclic Aromatic Hydrocarbon Biodegradation, Environ. Sci. Technol, 43 (2009) 7205-7211.

[61] H.Y.N. Holman, K. Nieman, D.L. Sorensen, C.D. Miller, M.C. Martin, T. Borch, W.R. McKinney, R.C. Sims, Catalysis of PAH Biodegradation by Humic Acid Shown in Synchrotron Infrared Studies, Environ. Sci. Technol, 36 (2002) 1276-1280. 
Table 1 Experimental treatment

\begin{tabular}{lll}
\hline Treatment & Code & Remarks \\
\hline DOM derived from S. superba & SD & S0, S2, S5, S8, S12 \\
DOM derived from P. elliottii & PD & P0, P2, P5, P8, P12 \\
DOM + phenanthrene + Phe-1 & DPP & treatment with DOM \\
DOM + Phe-1 & DP1 & control without phenanthrene \\
DOM+ phenanthrene & DP & control without bacteria \\
phenanthrene + Phe-1 & PP & control without DOM \\
phenanthrene + Phe-1 + NaN & PPN & control \\
PD + phenanthrene + Phe-1 & PDPP & treatment with PD \\
SD + phenanthrene + Phe-1 & SDPP & treatment with SD \\
PD + Phe-1 & PDP1 & control without phenanthrene \\
SD + Phe-1 & SDP1 & control without phenanthrene \\
PD + phenanthrene & PDP & control without bacteria \\
SD + phenanthrene & SDP & control without bacteria \\
\hline
\end{tabular}


Fig.1 Influence of litter species, decomposition time, and DOM concentration on degradation of phenanthrene

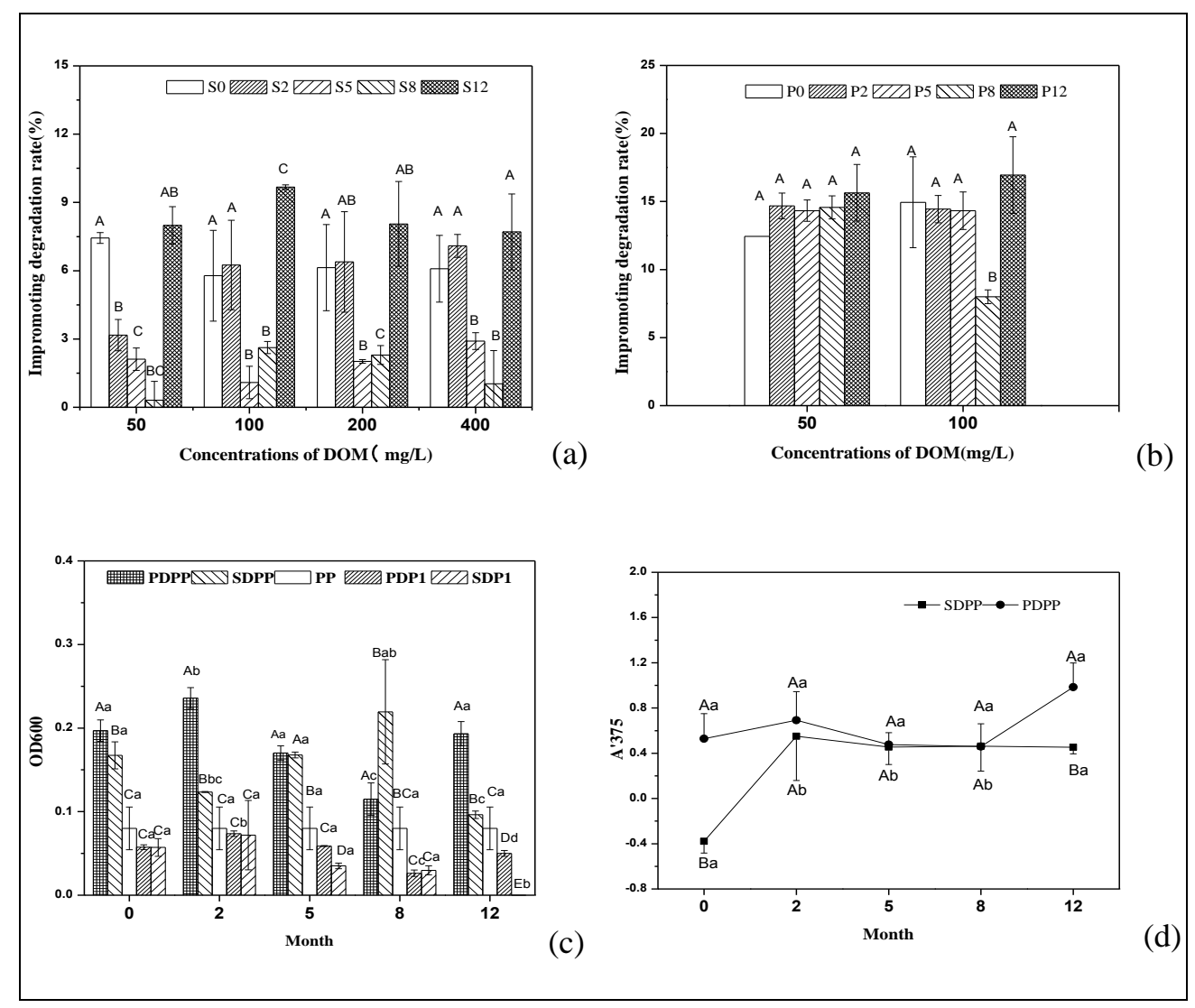

Fig. 1 The influence of DOM derived from P. elliottii (PD: P0, P2, P5, P8, P12) and S. superba (SD: S0, S2, S5, S8, S12) on degradation of phenanthrene (PA). (a) Promotion of PA degradation by SD; (b) promotion of PA degradation by PD; (c) effect of SD and PD on growth of Phe-1; (d) Phe-1 catechol 2,3-dioxygenase (C23O) activity during PA degradation. PDPP, PD+phenanthrene+Phe-1; PDP1, PD+Phe-1; SDPP, SD+phenanthrene+Phe-1; SDP1, SD+Phe-1; PP, phenanthrene+Phe-1; upper case letters indicate significant differences between treatments; lower case letters indicate significant differences between months. 
Fig.2 Mechanisms of DOM influence on phenanthrene degradation

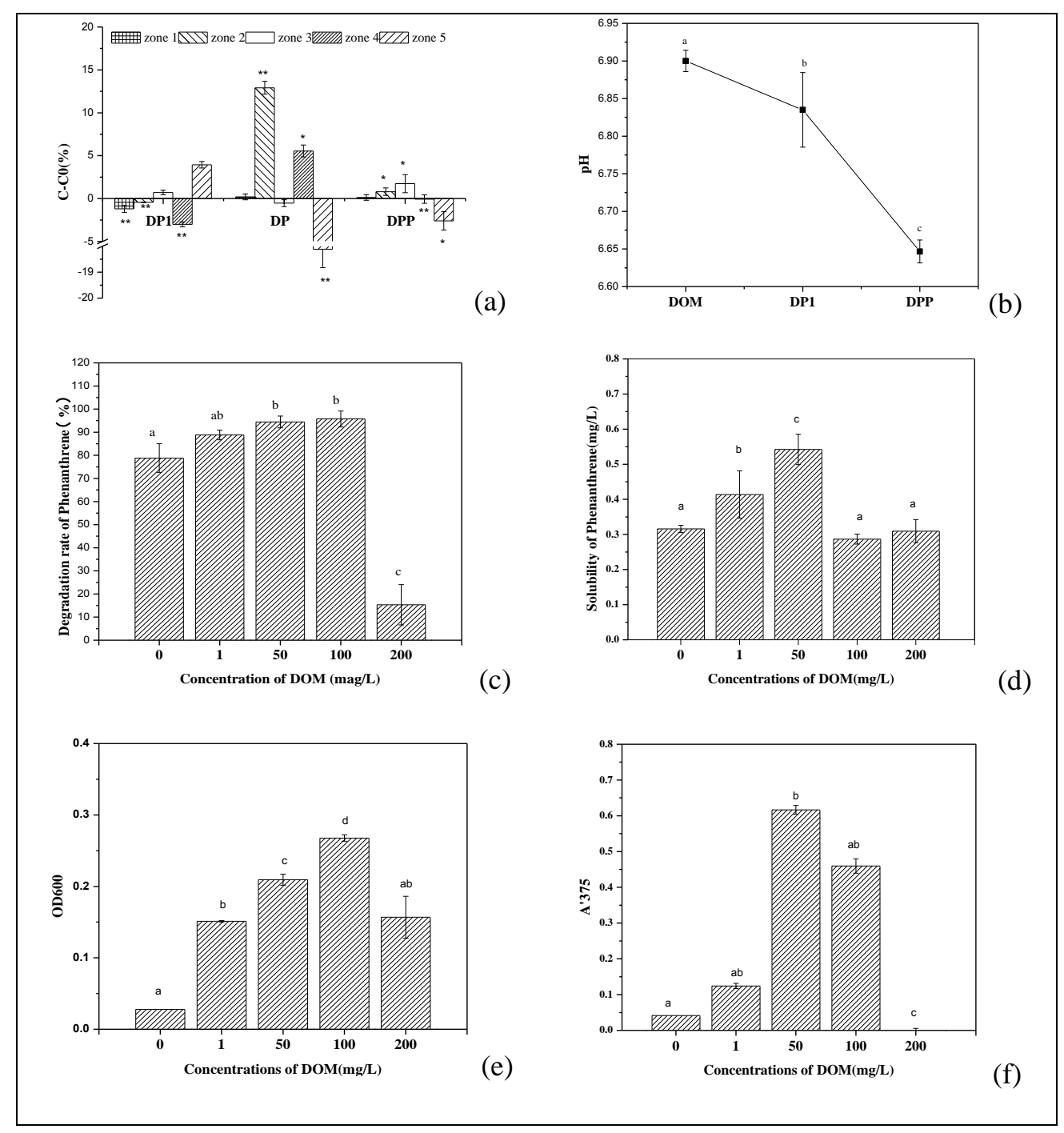

Fig.2 Effect of P12 (DOM derived from P. elliottii leaf litter that had decomposed for 12 months) on degradation of phenanthrene. (a) change in P12 (at with $100 \mathrm{mg} / \mathrm{L}$ ) composition before and after degradation of phenanthrene measured by EEMs-FRI; (b) effect of treatment on post-incubation $\mathrm{pH}$ in P12 with $100 \mathrm{mg} / \mathrm{L}$; (c) Phenanthrene degradation rate in different concentrations of P12; (d) solubility of phenanthrene; (e) growth of strain Phe-1 (OD600); (f) catechol 2,3-dioxygenase (C23O) activity of strain Phe-1 (A'375). DP1, DOM+Phe-1; DP, $\mathrm{DOM}+$ phenanthrene; DPP, DOM+phenanthrene+Phe-1; C-C0 $(\%)$, change in DOM content before (C0) and after (C) degradation; zones 1 and 2, aromatic protein and tyrosine; zone 3, fulvic acid (FA); zone4, soluble microbial by-products; zone5, humic acid (HA). ${ }^{*} \mathrm{P}<0.01 ; * \mathrm{P}<0.05$; uppercase letters indicate significant differences between months for SUV- $A_{254}$; lowercase letters indicate significant differences between months treatments. 
Fig.3 Degradation kinetics of phenanthrene in the presence of DOM

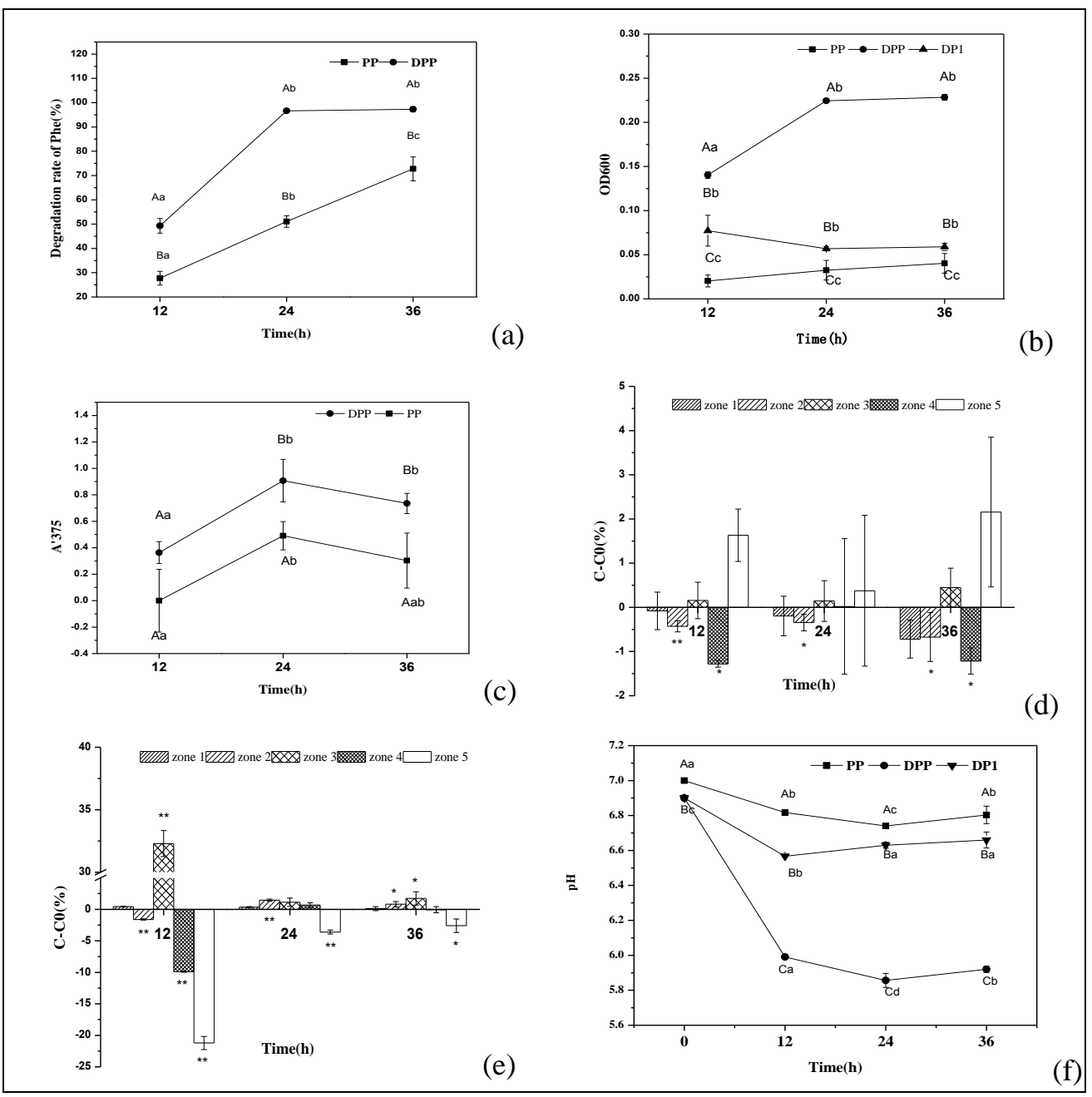

Fig. 3 Influence of DOM derived from P. elliottii leaf litter that had decomposed for 12 months (P12) on the time course of phenanthrene degradation. (a) Phenanthrene degradation rate; (b) Growth of strain Phe-1 (OD600); (c) Catechol 2,3-dioxygenase (C23O) activity of strain Phe-1 (A'375); (d) Change in DOM composition in treatment DP1; (e) Change in DOM composition in treatment DPP; (f) $\mathrm{pH}$ in different treatments. DP1, DOM+Phe-1; DPP, $\mathrm{DOM}+$ phenanthrene+Phe-1; PP, phenanthrene+Phe-1; $\mathrm{C}-\mathrm{C} 0(\%)$, difference in DOM content before $(\mathrm{C} 0)$ and after (C) degradation; zones 1 and 2, aromatic proteins and tyrosine; zone 3, fulvic acid (FA); zone 4, soluble microbial by-products; zone 5 , humic acid (HA). $* * \mathrm{P}<0.01$; $* \mathrm{P}<0.05$; uppercase letters indicate significant differences between treatments; lowercase letters indicate significant differences between concentrations. 
Graphical Abstract

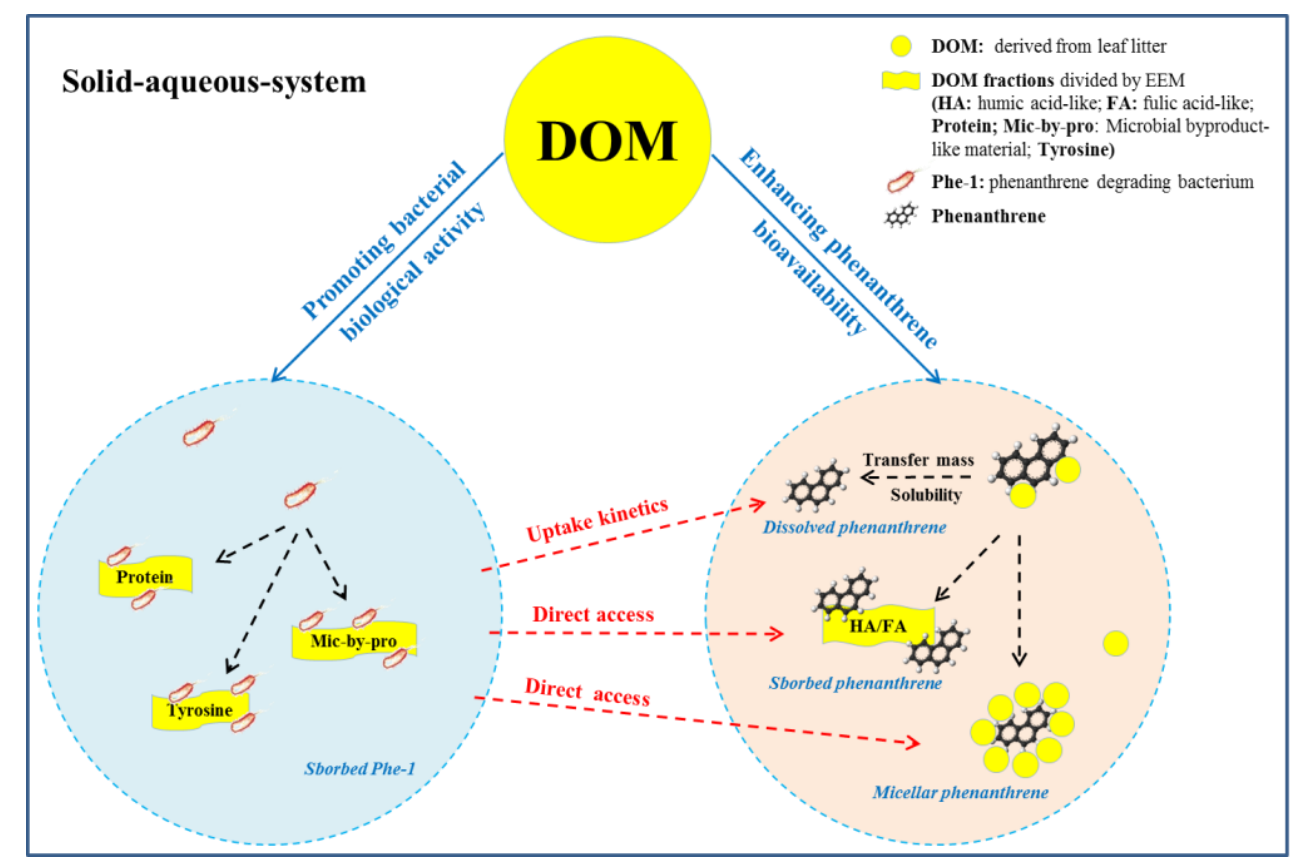

